\title{
Tailoring of Modern Polymer Based Deliverables: From Drug Delivery, Theranostics and Biomedical- A Review
}

\author{
Roberto Jetsu ${ }^{1}$, Dandyala Pavan Kalyan ${ }^{2 *}$, Hima Bindu Maroju ${ }^{3}$ \\ ${ }^{1}$ Professor, Department of Pharmacy, University of Verona, Italy \\ ${ }^{2}$ Department of Pharmacy Practice, Jawarharlal Nehru Technological University, Hyderabad, India \\ ${ }^{3}$ Professor, Department of Pharmaceutical Analysis, School of Pharmacy, Anurag Group of Institutions, Hyderabad, \\ India
}

*Address for Correspondence: Dr. Dandyala Pavan Kalyan, Intern, Department of Pharmacy Practice, Bharat Institute of Technology, Hyderabad, Telangana-501510, India

E-mail: kalyan6698@gmail.com

Received: 24 Sep 2020/ Revised: 31 Nov 2020/ Accepted: 28 Feb 2021

\begin{abstract}
In the use of engineered polymers, the development of advanced drug delivery systems was carried out. The invention of smart polymers that can respond to changes such as temperature, $\mathrm{pH}$ or the atmosphere has led to advancement in polymer chemistry. Both potential answers are swelling/decadence. Medication targeting has been carried out using drug-polymer conjugates and drug-containing nano/microparticles. Many amphiphilic block copolymers, which are strengthened by interconnected groups to enhance the stabilisation of micellar drug carriers, as well as block copolymers containing ligands that will enable selective medication delivery in the future will be discussed. The second process for improving the performance of prescription carriers is the addition of auxiliary agents. In emerging fields such as molecular imagery and nanotechnology, evolved polymers and polymer architectures have also been established. This study focuses on advanced polymers used for both traditional and more modern applications of nanotechnology.
\end{abstract}

Key-words: Biopolymer, Biomedical, Drug targeting, Drug delivery, Excipient, Theranostics

\section{INTRODUCTION}

The advances in polymer chemistry have paved the way for new technologies in drug delivery. These advances resulted in polymers with distinctive properties. Initially, polymers have been used as solubilizers and drug stabilizers and for continuing drug release mechanics. At that time, the roles of polymers have developed. A new synthetic method was developed to produce polymers with a well-defined structure ${ }^{[1-6]}$.

\section{How to cite this article}

Jetsu R, Kalyan DP, Maroju HB. Tailoring of Modern Polymer Based Deliverables: From Drug Delivery, Theranostics and Biomedical-A Review. SSR Inst. Int. J. Life Sci., 2021; 7(2): 2794-2800.

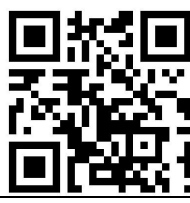

With the availability of new monomers, polymers with a range of phenotypes and personalized properties may be synthesized. As a result of feedback from other scientific fields such as biochemistry, microfluidics and nanotechnology, polymers and their pathways for drug delivery have gotten smarter and more efficiently. With the introduction of new polymers with unique properties, selecting the right polymers for particular applications is becoming exceedingly important. As a result, high demand has been made for safe and realistic vehicles for the transport of drugs. When new polymers were made available with new features, the market for polymers with more complex properties grew. Ideal, if advanced polymers are synthesized with unique drug delivery features such as medication solutions and drug targeting and for solving emerging problems ${ }^{[7-12]}$. As a consequence, the new drug delivery mechanisms and 
the peculiar features of polymers are beneficial to grasp. The main aims of this analysis are to provide an outline and describe future technology forecasts for advances in polymers and polymers for drug delivery. The numbers of publications discussing advanced drug delivery technologies have risen in recent years to enhance the time-scale and/or distribution management of the release. This analysis highlights some of the latest developments. Due to a large number of papers written and the small space for this report ${ }^{[12-20]}$, it is almost difficult to provide an outline of the topic. Rather, with new literature illustrations, wir selected two distinct approaches for designing advanced copolymer-based drug deliveries. In the remaining parts of this article, we explore the use of practical block copolymers and the use of auxiliary agents. Cross-connecting groups to block copolymers can enhance the stability and temporal regulation of the associated micelles.

Modern polymers for the design of theranostics- $A$ disease development usually requires several biological elements such as growth factors, enzymes, and leukocytes. To overcome this etiological problem, the concept of the therapeutic window can be generalized to include a therapeutic period so each variable's time frames become a crucial parameter. For eg, the ischemic brain induces multiple cellular activities, such as excitatory amino acid and reactive hour-long development of oxygen species, a day's creation of polymorphonuclear leucocyte, and macrophage activation throughout a week ${ }^{[21-30]}$.

The clinical time window can be used for tissue engineering depending on drug delivery. Normal tissues require temporary stimulus to achieve special function in the body during their growth. Several growth factors, such as the fibroblast growth factor, insulin-like growth factor, platelet-based growth factor, bone morphology protein transforming, vascular endothelial growth factor, etc., play a part in bone regeneration ${ }^{[31-38]}$. As an expansion of the pulsatile release scheme, a temporary drug release device is the perfect way to supply certain drugs. Sequential release of multiple drug components is only needed in this method (Fig. 1). In addition to programming, the controlled release system is also a major advantage in the on-site release of drugs. Techniques for targeting are commonly used to unleash on site. To optimise therapeutic effectiveness while minimising side effects this process strongly regularises the release of drugs. Drug release at a high local dose is limited for a long time to one particular target site. More controllability can generally be linked to the increased complexity of the structure. This is a key to the advancement of effective drug delivery systems, such as how to select an optimal drug delivery system and how to minimize the sophistication of the system ${ }^{[39-46]}$.

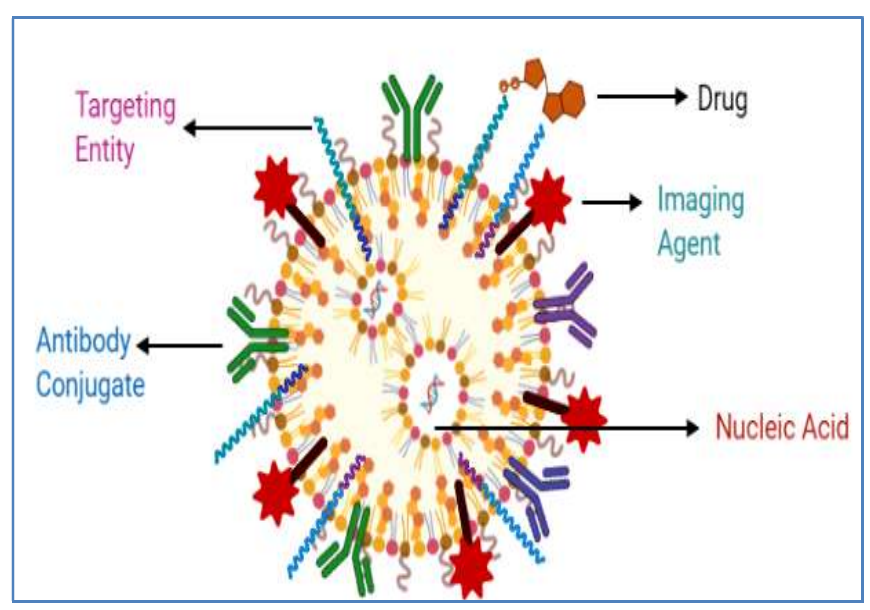

Fig. 1: Depicts the multifunctional application of polymer-based deliverables

Sensitive biopolymers for bioactive delivery- Polymers that react to biomolecules are interesting since they can be more accurate to physical or chemical stimuli than polymers. A well-known example of this is glucosesensitive polymers used for the treatment of diabetes with phenyl-boronic acid, glucose oxidase (GO) or concanavalin A (ConA). The release of insulin could be closely regulated by a system of closed-loop feedback in such systems. Their practical usefulness was sadly extremely limited. It was difficult to stop proteins like GOx and ConA, causing a polymer system's protein leakage and a host immune response. Besides, some monosaccharides may fight for binding glucose sites. Glutathione, which governs the cell redox state and mostly is present in the cytoplasm, is also an important molecule. Glutathione can easily break disulfide bonds in a polymer because of its great reduction activity. Michaels can grow when a disulfide is attached to a PEGend and good therapeutic efficacy can be achieved in vitro after endocytosis (ODN) and small ribonucleic acid (SiRNA). As most conditions equate with enzyme action, a great deal of interest has recently been gained by enzyme-sensitive polymer and polymeric structures. Polymer-doxorubicin combined with peptide bridges were planned for the discovery of doxorubicin from the 
tumour site, PEG-doxorubicin, N-(2-hydroxy-propyl) methacrylamide (HPMA). The Peptide Linkers had to be enzymatically degraded in the lysosome, leading to a high doxorubicin concentration in the target cells ${ }^{[47-56]}$. Polymer micelles have reported responding to protein kinase $A$ (PKA). PKA will increase the density of the negative charge and allow therapeutic genes to dissociate themselves from the polymer spine by the phosphorylation of PKA substrate peptides labelled by these micelles. Another important function of polymer conjugation is the solubility of poorly soluble medicines. The change is a little molecular compound often leads to a lack of bioactivity due to the structural-activity relationship. The high hydrophobicity of drugs that are not water-soluble leads often to their bioactivity. Nonetheless, several chemical changes may be made without causing a loss in the process. The feature groups already in the framework of medicines will combine water-soluble polymers to contribute to a significant increase in the solubility of drugs. Acid/base or enzymemediated hydrolysis may restore the original structure of medicine. The copolymers HPMA conjugating paclitaxel and doxorubicin are strong examples and many other polymer-drug conjugates in clinical trials are researched [57-78]. These polymer-medicinal combinations require however also a chemical modification of existing products which entails higher costs and the need for purification. Also, polymer conjugation generates new chemical medicines which require FDA authorization even if the original medicine has been licensed ${ }^{[79,80]}$.

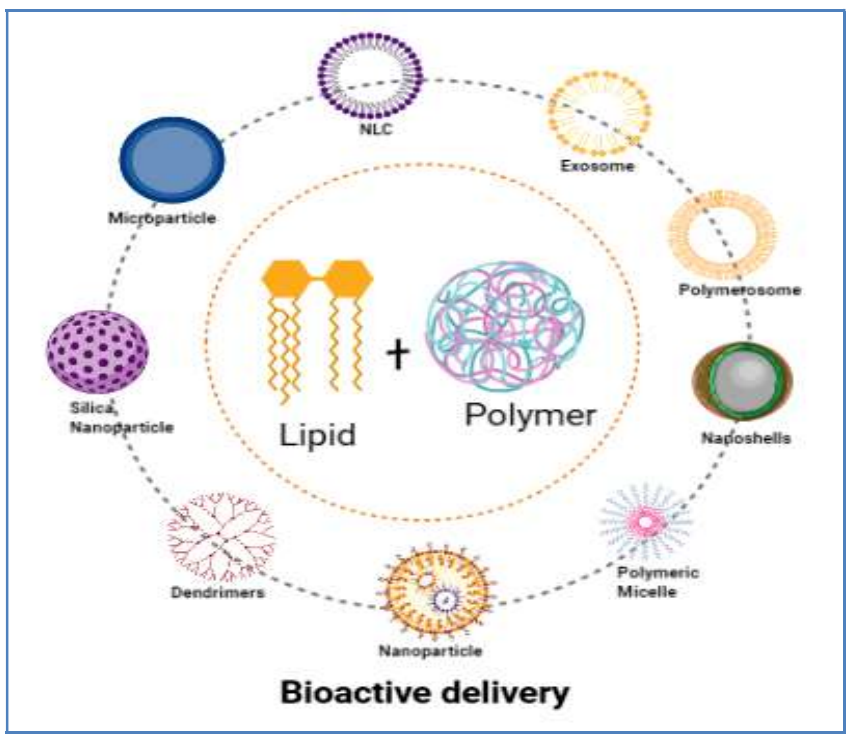

Fig. 2: Depicts the various deliverable systems for bioactive

\section{CONCLUSIONS}

Nanocarriers have been evolving with advances in the science and engineering of polymers in multifunctional application systems, such as controlled medicine distribution systems. To overcome and improve the vulnerabilities of conventional drug systems for spatiotemporal control of multiple drugs, sustained and pulsatile release systems, as well as polymer-drug conjugates, were created. Parallel synthesis is a useful way to identify new polymers suitable for various biomedical applications. Different methods of targeting and intelligent polymer networks guarantee to program and on line releases for therapeutic drugs. Currently, controlled medication supply networks incorporate a variety of components in one carrier and aim to fill different functions concurrently. Also, interdisciplinary research helps the development of more integrated and complex polymer structures not only to optimise therapeutic effectiveness but also for a single drugs carrier's multifunctional. But identifying clinically applicable medicines can be difficult given the various drug delivery systems available. The safety issue should often be taken into consideration when planning a new product since medication supply devices are meant to be inserted into the body. As anticipated, several drug carriers had significant problems with approval procedures and clinical trials. Study into a modern, more efficient method should then pursue efforts to establish a healthy and mass manufacturing system for medicinal drugs.

\section{CONTRIBUTION OF AUTHORS}

Supervision- Roberto Jetsu, Pavan Kalyan

Materials- Roberto Jetsu, Pavan Kalyan, Hima Bindu

Data Collection- Pavan Kalyan, Hima Bindu

Literature Search- Roberto Jetsu, Pavan Kalyan,

Writing Article- Roberto Jetsu, Pavan Kalyan, Hima Bindu Critical Review - Pavan Kalyan,

Article Editing- Roberto Jetsu, Pavan Kalyan, Hima Bindu

Final Approval- Roberto Jetsu, Pavan Kalyan

\section{REFERENCES}

[1] Yu Z, Xu Q, Dong C, Lee SS, Gao L, et al. Selfassembling peptide nanofibrous hydrogel as a versatile drug delivery platform. Curr Pharm Des., 2015; 21(29): 4342-54.

[2] Abdelhady S, Khaled MH, Mallesh K. Electro spunnanofibrous mats: a modern wound dressing matrix 
with a potential of drug delivery and therapeutics. J Eng Fibers Fabrics, 2015; 10(4): 179-93.

[3] Li WJ, Robert LM, Rocky ST. Electrospun nanofibrous scaffolds: production, characterization, and applications for tissue engineering and drug delivery. J Biomed Nanotechnol., 2005; 1(3): 259-75.

[4] Ahmed, Osama AA, Mallesh K, Zainy MB, Mohsen IA, et al. Quality by design coupled with near infrared in formulation of transdermal glimepiride liposomal films. J Pharma Sci., 2015; 104(6): 2062-75.

[5] Alhakamy NA, Osama AA, Mallesh K, et al. Chitosanbased microparticles enhance ellagic acid's colon targeting and proapoptotic activity. Pharm., 2020; 12(7): 652.

[6] Garg T, Goutam R, Amit KG. Biomaterials-based nanofiber scaffold: targeted and controlled carrier for cell and drug delivery. J Drug Targeting, 2015; 23(3): 202-21.

[7] Kurakula M, Raghavendra N. Electrospraying: A Facile Technology Unfolding the Chitosan based Drug Delivery and Biomedical Applications. Euro Polymer J., 2021; 110326.

[8] Yao Q, Yangxi L, Balaranjan S, Ranjit TK, Hongli S. Mesoporous silicate nanoparticles/3D nanofibrous scaffold-mediated dual-drug delivery for bone tissue engineering. J Controlled Release., 279 (2018): 69-78.

[9] Hasnain MS, Vema K, Mallesh K, Koteswara R, Mohammad $T$, et al. Use of alginates for drug delivery in dentistry. In Alginates in Drug Delivery, Academic Press; 2020; pp. 387-404.

[10]He C, Wei N, Wei F. Engineering of biomimetic nanofibrous matrices for drug delivery and tissue engineering. J Materials Chem., 2014; 45(2): 782848.

[11]Hasnain MS, Nayak AK, Kurakula M, Hoda MN. Alginate nanoparticles in drug delivery. In Alginates in Drug Delivery, 2020; pp. 129-52.

[12]Ji W, Fang $Y$, Hajar $S$, et al. Biocompatibility and degradation characteristics of PLGA-based electrospun nanofibrous scaffolds with nanoapatite incorporation. Biomaterials, 2012; 33(28): 6604-14.

[13]Hosny KM, Hibah M. Aldawsari RH, et al. Preparation, optimization, and evaluation of hyaluronic acid-based hydrogel loaded with miconazole self-nanoemulsion for the treatment of oral thrush. AAPS Pharm Sci Tech., 2019; 20(7): 1-12.
[14]Liu X, Xiaobing J, Peter XM. Nanofibrous hollow microspheres self-assembled from star-shaped polymers as injectable cell carriers for knee repair. Nature materials, 2011; 10 (5): 398-406.

[15]Kurakula M, Tarek AA. Co-delivery of atorvastatin nanocrystals in PLGA based in situ gel for antihyperlipidemic efficacy. Current drug delivery, 2016; 13(2): 211-20.

[16]Lu Q, Xiuli W, Shenzhou L, Mingzhong L, David LK, et al. Nanofibrous architecture of silk fibroin scaffolds prepared with a mild self-assembly process. Biomat., 2011; 32(4): 1059-67.

[17]Kurakula M, Osama AA, Usama AF, Tarek A. Solid lipid nanoparticles for transdermal delivery of avanafil: optimization, formulation, in-vitro and exvivo studies. J Liposome Res., 2016; 26(4): 288-96.

[18]Liang D, Benjamin SH, Benjamin C. Functional electrospun nanofibrous scaffolds for biomedical applications. Adv Drug Delivery Rev., 2007; 59(14): 1392-412.

[19]Kurakula M, El-Helw AM, Tariq RS, Magdy YA. Chitosan based atorvastatin nanocrystals: effect of cationic charge on particle size, formulation stability, and in-vivo efficacy. Inter J Nanomed., 2015; 10: 321.

[20]Shi Y, Yue L, Jianming W, Weiguo W, et al. A novel transdermal drug delivery system based on selfadhesive Janus nanofibrous film with high breathability and monodirectional waterpenetration.J Biomaterials Sci., Polymer Edition, 2014; 25(7): 713-28.

[21]Kurakula M, Koteswara R. Moving polyvinyl pyrrolidone electrospun nanofibers and bioprinted scaffolds toward multidisciplinary biomedical applications. Eur Polymer J., 2020; 109919.

[22]Miszuk JM, Jue H, Hongli S. Biomimetic Nanofibrous 3D Materials for Craniofacial Bone Tissue Engineering. ACS Appl Bio Materials, 2020; 3(10): 6538-45.

[23]Kurakula MN, Raghavendra N, Khushwant SY. Formulations for Polymer Coatings. Polymer Coatings: Technol Appl., 2020; 415-43.

[24]Monteiro N, Diana R, Albino M, Susana F, Nuno A, et al. Instructive nanofibrous scaffold comprising runtrelated transcription factor 2 gene delivery for bone tissue engineering. Acs Nano., 2014; 8(8): 8082-94.

[25]Fereiduni E, Ali G, Mohamed E. Characterization of composite powder feedstock from powder bed 
fusion additive manufacturing perspective. Materials, 2019; 12(22): 3673.

[26]Kim HS, Hyuk SY. MMPs-responsive release of DNA from electrospun nanofibrous matrix for local gene therapy: in vitro and in vivo evaluation. J Controlled Release, 2010; 145(3): 264-71.

[27]Kurakula M, Koteswara R, Vema K, Md Saquib $H$, Amit KN. Alginate-based hydrogel systems for drug releasing in wound healing. In Alginates in Drug Delivery, Academic Press, 2020; pp. 323-58.

[28]Xi Y, Juan G, Yi G, Bo L, Peter XM. Biomimetic elastomeric polypeptide-based nanofibrous matrix for overcoming multidrug-resistant bacteria and enhancing full-thickness wound healing/skin regeneration. ACS nano, 2018; 12, 11: 10772-84.

[29]Rao K, Mallesh K, Khushwant SY. Application of Electrospun Materials in Gene Delivery. Electrospun Materials Allied Appl., 2020: 265-306.

[30]Holzwarth JM, Peter XM. Biomimetic nanofibrous scaffolds for bone tissue engineering. Biomaterials, 2011; 32(36): 9622-29.

[31]Kurakula M, Koteswara R. Pharmaceutical Assessment of Polyvinylpyrrolidone (PVP): As Excipient from Conventional to Controlled Delivery Systems with a Spotlight on COVID-19 Inhibition. J Drug Delivery Sci Technol., 2020: 102046.

[32]Hakkarainen E, Arle K, Ivo L, Andres L, Kristian S, et al. Comparison of traditional and ultrasoundenhanced electrospinning in fabricating nanofibrous drug delivery systems. Pharma., 2019; 11(10): 495.

[33]Kurakula M, Tariq RSobahi, El-Helw AM, Magdy YA. Development and validation of a RP-HPLC method for assay of atorvastatin and its application in dissolution studies on thermosensitive hydrogelbased nanocrystals. Tropical J Pharma Res., 2014; 13(10): 1681-87.

[34]Bagó JR, Guillaume JP, Onyi O, Mahsa MA, Elizabeth $\mathrm{GL}$, et al. Electrospun nanofibrous scaffolds increase the efficacy of stem cell-mediated therapy of surgically resected glioblastoma. Biomaterials, 2016; 90: 116-25.

[35]Kurakula MC, Nagasree K, Prakash VD. Formulation and evaluation of prednisolone proliposomal gel for effective topical pharmacotherapy. Inter J Pharma Sci Drug Res., 2012; 4(1): 35.

[36]Bacakova L, Marketa B, Julia P, Radmila K, Lubica S, et al. Nanofibrous scaffolds as promising cell carriers for tissue engineering. In Nanofiber ResearchReaching New Heights, Intech Open, 2016; pp. 29-53.

[37]Mallesh K, Nikitha P, Chowdary P, Kumar R. Piroxicam proliposomal gel: a novel approach for tropical delivery. J Pharma Res., 2012; 5(3): 1755-63.

[38]Kurakula M, Abdul BM, Rao PA, Prakash VD. Estimation of piroxicam in proliposomal formulation using RPHPLC method. Int J Chem Anal Sci., 2011; 2(9): 1193-96.

[39]Kurakula MN, Raghavendra N. Prospection of recent chitosan biomedical trends: Evidence from patent analysis (2009-2020). Int J Biol Macromolecul., 2020; 165(Pt B): 1924-38.

[40]Sun J, Huaping T. Alginate-based biomaterials for regenerative medicine applications. Materials, 2013; 6(4): 1285-309.

[41]Venkatesh $M$, Kurakula $M$. Self-nano emulsifying drug delivery system (SNEDDS) for oral delivery of atorvastatin-formulation and bioavailability studies. J Drug Delivery Therapeutics, 2013; 3(3): 131-40.

[42]Lee S, Jung SK, Hun SC, Go WK, Jong IW, et al. Electrospun nanofibrous scaffolds for controlled release of adeno-associated viral vectors. Acta Biomaterialia, 2011; 7(11): 3868-76.

[43]Diwan PV, et al. Estimation of Prednisolone in Proliposomal formulation using RP HPLC method. 2011; 2(9): 1193-96.

[44]Chan OCM, So KF, Chan BP. Fabrication of nanofibrous collagen microspheres for protein delivery and effects of photochemical crosslinking on release kinetics. J Controlled Release, 2008; 129(2): 135-43.

[45]Murali VP, Tomoko F, Caleb G, et al. Modified electrospun chitosan membranes for controlled release of simvastatin. Int J Pharma., 2020; 119438.

[46]Feng ZQ, Xuehui C, Ning PH, Tao W, et al. The effect of nanofibrous galactosylated chitosan scaffolds on the formation of rat primary hepatocyte aggregates and the maintenance of liver function. Biomaterials, 2009; 30 (14): 2753-63.

[47]Naveen NR, Kumar SB, Uma TS, Natrajan TS, Sehgal PK. Synthesis of nonwoven nanofibers by electrospinning-a promising biomaterial for tissue engineering and drug delivery. Adv Eng Materials, 201012 (8): B380-87.

[48]Kalmer RR, Maedeh M, Ghasem N, Mortaza G, Yaghoub $\mathrm{H}$, et al. Fabrication of multifunctional microfibrous and nanofibrous cellulose carriers and 
comparison of cell adhesion and spreading potential on them. Biointerface Res Appl Chem., 2020; 10(3): 5387-91.

[49]Pilehvar-Soltanahmadi $Y$, Mehdi $D$, Abbas $M$, et al. An overview on application of natural substances incorporated with electrospun nanofibrous scaffolds to development of innovative wound dressings. Mini reviews Medicinal Chem., 2018; 18(5): 414-27.

[50]Naveen NR, Chakka G, Mallesh K. Okra-Thioglycolic acid conjugate-Synthesis, characterization, and evaluation as a mucoadhesive polymer. Processes, 2020; 8(3): 316.

[51]Naveen NR, Chakka G, Mallesh K. Okra-Thioglycolic acid conjugate-Synthesis, characterization, and evaluation as a mucoadhesive polymer. Processes, 2020; 8(3): 316.

[52]Raghavendra NN, Kurakula M, Gowthami B. Process optimization by response surface methodology for preparation and evaluation of methotrexate loaded chitosan nanoparticles. Materials Today: Proceedings, 2020; 33(7): 2716-24.

[53]Jayarama R, Venugopal SR, Rajeswari R, Shayanti M, Ramalingam B, et al. Nanofibrous structured biomimetic strategies for skin tissue regeneration. Wound Repair Regeneration, 2013; 21(1): 1-16.

[54]Ingavle GC, Kent L. Advancements in electrospinning of polymeric nanofibrous scaffolds for tissue engineering. Tissue Eng Part B Rev., 2014; 20(4): 27793.

[55]Vanitasagar SC, Srinivas NJ, Subhashini P, Mallesh LA. Solid dispersion-a comparative study on the dissolution rate of aceclofenac. Int J Pharm Pharmaceutical Sci., 2012; 4(3): 274-78.

[56]Zhong W, Malcolm MQX, Howard IM. Nanofibrous materials for wound care. Cutaneous Ocular toxicol., 2010; 29(3): 143-52.

[57]Hosny KM, Nabil AA, Maeen AA, Mallesh K, Alshaimaa $M A$, et al. Self-Nanoemulsifying System Loaded with Sildenafil Citrate and Incorporated within Oral Lyophilized Flash Tablets: Preparation, Optimization, and In Vivo Evaluation. Pharmaceutics, 2020; 1211: 1124.

[58]Prabaharan M, Jayakumar R, Nair SV. Electrospun nanofibrous scaffolds-current status and prospects in drug delivery. Biomedical applications of polymeric nanofibers, 2011: 241-62.
[59]Modica de ML, Alison VK, Maria de FP, Bahijja TR. Engineering of nanofibrous amorphous and crystalline solid dispersions for oral drug delivery. Pharmaceutics, 2019; 11 (1): 7.

[60]Kurakula M. Probiotics in Lung Cancer: An Emerging Field of Multifarious Potential and Opportunities. In Probiotic Research in Therapeutics, pp. 125-158. Springer, Singapore, 2021.

[61]Li WJ, Robert LM, Rocky ST. Electrospun nanofibrous scaffolds: production, characterization, and applications for tissue engineering and drug delivery. J Biomed Nanotechnol., 2005; 1(3): 259-75.

[62]Basim P, Gorityala S, Kurakula M. Advances in Functionalized Hybrid Biopolymer Augmented Lipidbased Systems: A Spotlight on Their Role in Design of Gastro Retentive Delivery Systems. Biopolymers, 2021, pp. 4.

[63]Basha SK, Dhandayuthabani R, Muzammil MS, Kumari VS. Solid lipid nanoparticles for oral drug delivery. Materials Today: Proceedings, 2021, pp. 313-24.

[64]Jeengar MK, Mallesh K, Poonam P, Ashwini M, Ramakrishna S, Deepti P. Antiviral activity of stearylamine against chikungunya virus. Chem Physics Lipids, 2021; 235: 105049.

[65]Wang C, Xiaoguang S, Huijuan S, Chuangnian Z, Xiaoli $W$, et al. Polymer-lipid hybrid nanovesicle-enabled combination of immunogenic chemotherapy and RNAi-mediated PD-L1 knockdown elicits antitumor immunity against melanoma. Biomaterials, 2021; 268: 120579.

[66]Luo MX, Hua S, Shang QY. Application of nanotechnology in drug delivery systems for respiratory diseases. Mol Medicine Reports, 2021; 23(5), pp. 1-17.

[67]Kurakula M, Raghavendra N. Electrospraying: A Facile Technology Unfolding the Chitosan based Drug Delivery and Biomedical Applications. European Polymer J, 2021: 110326.

[68]Vieira ACC, Luíse LC, Marina P, Sofia CL, Pedro José $\mathrm{RN}$, et al. Lipid nanoparticles coated with chitosan using a one-step association method to target rifampicin to alveolar macrophages. Carbohydrate Polymers, 2021; 252: 116978.

[69]Topal GR, Maria M, Gergo P, Aniko S, Tamas FP, et al. ApoE-Targeting Increases the Transfer of Solid Lipid Nanoparticles with Donepezil Cargo across a Culture 
Model of the Blood-Brain Barrier. Pharmaceutics, 2021; 13(1): 38.

[70]Sabir F, Maimoona Q, Asim UR, Nasir MA, Gul MK, et al. An Efficient Approach for Development and Optimization of Curcumin Loaded Solid Lipid Nanoparticles' Patch for Transdermal Delivery. J Microencapsulation, 2021; 1-34.

[71]Devnarain N, Nawras O, Victoria OF, et al. Intrinsic stimuli responsive nanocarriers for smart drug delivery of antibacterial agents-An in depth review of the last two decades. Wiley Interdisciplinary Reviews: Nanomedicine Nanobiotechnol., 2021; 13 (1): e1664.

[72]Kurakula M, Basim P, Biopolymer-Lipid Hybrid Composites and their Advances in Bio-imaging and Drug Delivery. J Radiol Med Imaging, 2021; 4(1): 1041.

[73]Hart N, Friederike A, Olivia MM. From adsorption to covalent bonding: Apolipoprotein $\mathrm{E}$ functionalization of polymeric nanoparticles for drug delivery across the blood-brain barrier. Adv Therapeutics, 2021; 4(1): 2000092.

[74]Witwer KW, Joy W. Extracellular vesicles versus synthetic nanoparticles for drug delivery. Nature Rev Materials, 2021; pp. 1-4.
[75]Pradhan D, Prativa B, Amit G, Goutam G, Goutam R. Recent Advancement in Nanotechnology-Based Drug Delivery System Against Viral Infections. AAPS Pharm Sci Tech., 2021; 22(1): 1-19.

[76]Kurakula M, Koteswara R, Khushwant SY. Fabrication and characterization of polycaprolactone-based green materials for drug delivery. In Applications of Advanced Green Materials. Woodhead Publishing, 2021; pp. 395-423.

[77]Omidi Y, Nazanin K, Young K, Hossein O. Drug delivery and targeting to brain tumors: considerations for crossing the blood-brain barrier. Expert Rev Clin Pharmacol., 2021.

[78]Angarita-Villamizar AV, Elsa RA, Ivonne LD, Leon DP. Amphiphilic copolymers modified with oleic acid and cholesterol by combining ring opening polymerization and click chemistry with improved amphotericin B loading capacity.J Polymer Res., 2021; 28(1): 1-14.

[79]Kurakula M, Koteswara R. Probiotics in Lung Cancer: An Emerging Field of Multifarious Potential and Opportunities. Probiotic Res Therapeutics, 2021; pp. 125-58.

[80]Perez BY, Bianca de Carvalho FT, Eliana LFM, Ana MCR. Biocompatible Lipid Polymer Cationic Nanoparticles for Antigen Presentation. Polymers, 2021; 13(2): 185. 